\title{
Literatura infantil digital: leitura na tela e novas formas de socialização na escola
}

\author{
Digital children's literature: screen reading and new forms of socialization at school
}

\section{Literatura infantil digital: lectura de pantalla y nuevas formas de socialización en la escuela}

\section{Rafaela Vilela*}

\section{Resumo}

O artigo apresenta resultados de uma pesquisa de doutorado e discute a leitura contemporânea e as novas formas de socialização na escola em diálogo com a literatura infantil digital. Como a literatura infantil se apresenta na tela? Que características, recursos e funcionalidades a definem? Como as crianças leem esse dispositivo no espaço coletivo da escola? Como a leitura na tela impacta os processos de socialização na escola? Para responder as questões, foram realizadas ações propositivas a partir da leitura de nove aplicativos literários em uma escola pública federal de educação infantil com um grupo de crianças de 5 e 6 anos. O texto está organizado em três partes: na primeira traz considerações sobre literatura infantil digital, em seguida, apresenta instantes que abordam a leitura colaborativa de aplicativos literários e o compartilhamento de saberes produzidos por uma comunidade de leitores, por fim, nas considerações finais, discute a experiência de ler e de dialogar sobre o lido.

Palavras-chave: literatura infantil digital; educação infantil; comunidade de leitores.

\section{Abstract}

This article presents the results of a doctoral research and discusses contemporary reading and new forms of socialization at school in dialogue with digital children's literature. How the childhood literature presents on the screen? What characteristics, resources and functionalities define them? What has been produced in digital children's literature in Brazil? How children reed these devices in the collective space of the school? How does reading on the screen impact socialization processes at school? To answer these questions, proposal actions involving digital children's literature in a group of children with 5 and 6 years old in a public federal childhood school. This text is organized in three parts: the first brings considerations about digital children's literature, then presents moments that address the collaborative reading of apps and the sharing of knowledge produced by a community of readers, finally, in the final considerations, discusses the experience of reading and talking about what is read.

Keywords: digital children's literature; kindergarten; community of readers.

Recebido em: 30/07/2020 - Aprovado em: 15/04/2021

http://dx.doi.org/10.5335/rep.v28i1.11488

Doutora em Educação pela Universidade Federal do Rio de Janeiro. Professora do Colégio de Aplicação da Universidade Federal do Rio de Janeiro. Orcid: https://orcid.org/0000-0003-2761-6385. E-mail: rafalouise@gmail.com 


\section{Resumen}

Este artículo presenta los resultados de una investigación doctoral y analiza la lectura contemporánea y las nuevas formas de socialización en la escuela en diálogo con la literatura infantil digital. ¿Cómo aparece en la pantalla la literatura infantil? ¿Qué características, características y funcionalidad la definen? ¿Cómo leen los niños este dispositivo en el espacio colectivo de la escuela? ¿Cómo afecta la lectura en pantalla a los procesos de socialización en la escuela? Para responder a estas preguntas, se tomaron medidas proposicionales basadas en la lectura de nueve aplicaciones literarias en una escuela pública federal de Educación de la Primera Infancia con un grupo de niños de 5 y 6 años. El texto está organizado en tres partes: la primera trae consideraciones sobre la literatura infantil digital, luego presenta momentos que abordan la lectura colaborativa de aplicaciones literarias y el intercambio de conocimiento producido por una comunidad de lectores, finalmente, en las consideraciones finales, analiza la experiencia de leer y hablar sobre lo que se lee.

Palabras clave: literatura infantil digital; educación infantil; comunidad de lectores.

\section{Introdução}

O presente artigo apresenta resultados de uma pesquisa de doutorado (VILELA, 2019) e discute a leitura contemporânea e as novas formas de socialização na escola em diálogo com a literatura infantil digital. Enquanto expressão contemporânea de arte para ser lida exclusivamente em meio digital, a literatura infantil digital convida o leitor a provar uma obra que articula texto, imagem, movimento, som e interatividade. Como a literatura infantil se apresenta na tela? Que características, recursos e funcionalidades a definem? Como as crianças leem esse dispositivo no espaço coletivo da escola? Como a leitura na tela impacta os processos de socialização na escola?

Uma discussão contemporânea, do "tempo de agora" (BENJAMIN, 2012), que compreende que a revolução digital não se traduz apenas como um processo técnico e sim como uma alteração nos modos dos sujeitos produzirem e consumirem informações, pois como anuncia Martín-Barbero (2006, p. 54), "a tecnologia remete, hoje, não a alguns aparelhos, mas, sim, a novos modos de percepção e de linguagem, a novas sensibilidades e escritas".

A pesquisa empírica foi realizada entre os meses de julho e outubro de 2018 em uma escola pública federal de educação infantil de uma grande capital com um grupo de crianças de 5 e 6 anos. Pautada na premissa de que a literatura infantil digital é um campo novo de conhecimento e, por isso, uma tecnologia ainda pouco presente nas escolas, foram realizadas ações propositivas a partir da leitura de nove aplicativos literários: "Crianceiras", "Pequenos grandes contos de verdade", "Monstros do Cinema", "Quanto bumbum!", "Sua história maluquinha”, "Mini Zoo”, "Mãos mágicas", "Chomp" e "Via Láctea”. 
A proposta de olhar para os artefatos feitos para as crianças, em diálogo com elas, constituiu-se como um importante princípio teórico-metodológico. Um princípio que compreende as crianças enquanto sujeitos constituídos na e pela linguagem e que, portanto, têm muito o que dizer, possibilitando uma reflexão potente sobre o nosso tempo e a nossa cultura.

Bakhtin (2011, p. 395) afirma que "o objeto das ciências humanas é o ser expressivo e falante". Diferentemente das ciências exatas em que o pesquisador contempla uma coisa e emite uma explicação sobre ela, nas ciências humanas a pesquisa se constitui como um processo dialógico e alteritário que envolve dois sujeitos, duas consciências. Um movimento que, como afirma Pereira (2012, p. 62), "pressupõe uma ativa relação entre os sujeitos que se põem em diálogo, o tema sobre o qual eles dialogam e o contexto no qual esse diálogo se dá".

Nesse sentido, assumimos a pesquisa intervenção como lugar de ação e reflexão. Um "agir com" que permite ao pesquisador e ao pesquisado se constituírem nesse processo pois, enquanto sujeitos da linguagem, ambos encontram nessa relação alteritária os fundamentos de um investigar compartilhado que envolve os movimentos de "encontrar, compartilhar e transformar" (MACEDO et al., 2012).

As ações propositivas foram registradas a partir de uma metodologia dialógica, denominada captura de instantes (VILELA, 2019), na qual as percepções infantis foram apreendidas a partir do cruzamento de três pontos de observação: registros elaborados por mim, coordenadora da pesquisa; registros realizados por uma pesquisadora-assistente e filmagens. A articulação desses três planos propiciou a captura de diferentes texturas do instante vivido.

Os encontros com as crianças apontaram que quase todas possuíam tablet. A intimidade em manusear o dispositivo durante as ações propositivas apenas confirmou o acesso que elas têm a esses aparelhos fora da escola. As crianças conheciam os movimentos de ligar e desligar e passavam com agilidade as telas em busca dos ícones dos aplicativos, clicando nos escolhidos sem qualquer dificuldade. A preferência por jogos e vídeos, o desejo de assistir a vídeos de youtubers famosos e o movimento tímido de pesquisa na rede, até mesmo por não estarem alfabetizadas e não terem autonomia de leitura, indicam a importância de pensarmos a relação das crianças com a cultura digital.

Observamos que o encontro com a literatura infantil digital proporcionou ao grupo um respiro dentro da lógica digital contemporânea. A pesquisa apontou que, independentemente do suporte, o encontro com a literatura permite a suspensão do tempo cronológico. As crianças, ao deslocarem-se por distintos tempos e espaços, 
experimentam a dimensão expressiva da linguagem. Um mergulho que envolveu os movimentos de imitar-repetir-criar, provocando novos encontros consigo, com o outro e com o mundo, em um trânsito intermitente entre realidade e fantasia. Reflexões que potencializam as discussões sobre a leitura contemporânea e as novas formas de socialização na escola.

$\mathrm{O}$ artigo está organizado em três partes: na primeira traz considerações sobre literatura infantil digital, em seguida, apresenta instantes que abordam a leitura colaborativa de aplicativos literários e o compartilhamento de saberes produzido por uma comunidade de leitores, por fim, nas considerações finais, discute a experiência de ler e de dialogar sobre o lido.

\section{Quando 0 digital é literatura? Limiares na tela}

Por considerar a literatura infantil digital como uma nova forma de expressão da cultura contemporânea, Ramada Prieto (2017, 2018) defende a ficção digital como um ecossistema, entendendo que esta nova forma de fazer literatura, apesar de compartilhar aspetos fundamentais com as esferas que compõem o universo de ficção infantil e juvenil, demonstra especificidades. Para isso, o pesquisador catalão destaca quatro linhas de expressão que ajudam a definir e a caracterizar a identidade da literatura infantil e juvenil digital: i) a mudança da materialidade, ii) a presença da multimodalidade, iii) a participação como uma nova relação entre autor e leitor e iv) a ruptura da linearidade textual.

A primeira linha de expressão aborda a materialidade da obra. Diferentemente do livro impresso, a literatura infantil digital apresenta-se ao leitor por meio de um ecossistema, transformando a natureza do objeto e o contexto de comunicação literária (RAMADA PRIETO, 2018, p. 19). Isto representa uma mudança tanto na produção quanto na recepção da obra. Compreendemos, nessa vertente, que a literatura infantil digital inaugura uma nova cadeia de produção. De acordo com os pesquisadores Menegazzi, Sylla e Padovani (2018, p. 46), como as obras digitais apresentam uma grande variedade de recursos tecnológicos e multimídias, a produção editorial exige que "o grupo tradicional de profissionais do mundo editorial - autores, editores, tradutores, ilustradores e designers gráficos -, [seja] somado a compositores, locutores, programadores de jogos”. Essa nova lógica desloca a ideia de um único autor para uma proposta centrada na concepção de inteligência coletiva (LEVY, 1999), estimulando a participação coletiva e a sinergia dos saberes. Princípios que aproximam pessoas em torno de interesses comuns, com o intuito 
de construírem conhecimentos cada vez mais colaborativos. Nesse caso, ao alterar o modo como são produzidas as ficções literárias, altera-se diretamente a recepção, posto que novas referências e percepções sobre a literatura infantil digital e sobre a comunicação literária podem ser criadas na relação entre leitor e obra.

A multimodalidade, segunda linha de expressão apontada por Ramada Prieto (2017, 2018), configura-se como uma importante característica das obras literárias digitais, sendo compreendida como um elemento definidor desta produção estética (HAYLES, 2008). A comunicação literária digital abrange a apropriação de diferentes substâncias expressivas, envolvendo a convergência entre as linguagens. Nesse sentido, o discurso literário é construído a partir de diferentes camadas de sentidos e envolvem o som - em todas as suas vertentes, a imagem - estática e em movimento, o texto oral, o texto escrito, o cinema e a linguagem dos jogos eletrônicos. Ao olharmos para a produção literária infantil, observamos que a multimodalidade surge antes mesmo da literatura infantil digital se consolidar como gênero. É o livro ilustrado que inaugura a relação entre imagem e palavra, entendendo ambas como matéria-prima literária, apresentando ao leitor uma produção multimodal (NIKOLAJEVA; SCOTT, 2011).

A terceira linha de expressão destacada é a participação do leitor na obra, a transformação da relação entre autor e leitor dentro do texto literário. Assim, embora a interatividade possa ser tida como elemento central da literatura infantil digital, para o pesquisador, ela pode representar um mero adorno tecnológico. Um recurso que embora permita a interação através de cliques, pode não permitir a entrada do leitor na obra de fato. Para Ramada Prieto (2017, 2018), o conceito de participação relaciona-se a uma ação que é intencional e que abarca os recursos de interatividade. Por não se configurar como texto linear, as ficções literárias são tecidas a cada leitura a partir da participação do leitor. Essa exploração aberta resulta em experiências ficcionais distintas, permitindo, em alguns casos, a cocriação literária. Um movimento em que a participação do leitor deixa marcas dentro do universo ficcional proposto.

Por fim, a ruptura da linearidade textual é defendida como uma questão que modifica a estrutura dos textos digitais e que instaura novos modos de ler. A natureza hipertextual do texto digital altera o modo como a informação é organizada nas obras digitais e rompe com a perspectiva de uma história que tem princípio, meio e fim. Pautada numa lógica não sequencial e programada, que envolve a convergência de linguagens, a literatura infantil digital prevê a liberdade de navegação do leitor. O caminho adotado não é o mesmo para cada ato de leitura, como 
na tradição impressa. Há, nesse sentido, uma multiplicação quase exponencial de possíveis arquiteturas estruturais que organizam os textos literários, gerando novas formas de ler e de se relacionar com as ficções.

Considerando as linhas de expressão propostas pelo pesquisador catalão, defendo neste artigo a literatura infantil digital como um espaço tempo limiar onde a literatura, o cinema, a música e os jogos eletrônicos se encontram. A limiaridade presente nas ficções digitais é o que instaura a possibilidade de os leitores transitarem entre os diferentes territórios semióticos e de, nesse ir e vir, construírem suas experiências de leitura.

O termo limiar vem do latim limes, que originou a palavra limite em português, sendo usado também para designar as fronteiras do Império Romano. Para Walter Benjamin (2006, não paginado), entretanto, "o limiar deve distinguir-se claramente da fronteira. Limiar é uma zona e na palavra estão contidos os sentidos de mudança, passagem, flutuação”. A fronteira, nessa vertente, pode ser compreendida como um traço de união e separação entre dois pontos: ao cruzar a fronteira, atravessamos uma linha, chegamos a um outro lugar. O limiar, enquanto zona, pressupõe um transitar com idas e vindas. Uma forma de olhar para o mundo que considera o desvio como método.

É com essa premissa, a da limiaridade, que Walter Benjamin configura seus escritos. Fragmentos tecidos em um ir e vir permanente, repletos de desvios. $\mathrm{O}$ filósofo discute história, linguagem, arte e política a partir da lógica do pensamento imagético, alegórico, capaz de retirar os objetos dos seus contextos habituais para neles encontrar novas significações, oferecendo uma nova mirada do mundo. Nesse sentido, arrisca-se a usar um método que "não separa o pensamento da forma do pensamento, e, sobretudo, que escolhe como objeto e lugar privilegiado desse pensamento, não o espaço interior e já delimitado dos saberes, mas precisamente o limiar, a fronteira, o lugar-entre" (BARRENTO, 2012, p. 42, grifos do autor). Um movimento não linear que considera o saber como um espaço tempo que se renova na e pela palavra, posto que a linguagem é lugar de vida e de pensamento.

A obra de Walter Benjamin, nessa indissociação entre forma e conteúdo, reafirma que o pensamento não é algo acabado. É nesse sentido que Barrento (2012, p. 43) considera que os textos do filósofo compõem "uma cartografia de limiares: a partir de uma aglomeração aparentemente caótica de textos, fragmentos, cartas, experiências, relações, sem limites nem sistema aparente (BARRENTO, 2012, p. 43). Uma estrutura descontínua, tal como observamos na literatura infantil digital, que provoca o leitor a experimentar a imersão e a montagem como modos 
de transitar entre os diferentes conceitos e criar sentidos próprios. Movimentos que envolvem a busca de semelhanças entre os fragmentos apreendidos e que ganham sentido no olhar do outro. Acabamentos éticos e estéticos sempre provisórios, temporários, pois apesar de cada objeto carregar em si mesmo a sua história e o seu valor, é no e pelo contexto da relação com os demais objetos que esse valor se potencializa e se revigora (PEREIRA, 2012, p. 34).

Nesse viés, compreendo que a ficção digital surge na tela substituindo as fronteiras encontradas no impresso, definidas através de margens e enquadres, por um trânsito nos limiares da linguagem. Ao propor olhar a literatura infantil digital como limiar, defendo-a como um espaço tempo de encontro com diferentes linguagens. Experiências de leitura tecidas em um ir e vir permanente, que potencializam a produção de sentidos ampliando o caráter estético, lúdico e alteritário que institui a literatura.

\section{Leitura digital em rede: colaboração e compartilhamento de saberes na escola}

Para Roger Chartier (1998), o encontro entre um grupo de pessoas que se reúne com frequência para ler e compartilhar experiências de leitura é o que institui uma comunidade de leitores. Um espaço tempo para que os sujeitos estabeleçam relações com o universo literário, compartilhando e comentando leituras. Essa prática coletiva potencializa a construção e a negociação de sentidos. "Essa partilha - de leituras, ideias e sentimentos - favorece a construção de uma comunidade com referências e cumplicidades mútuas, onde as ressonâncias individuais da literatura extrapolam os sujeitos e formam elos de coletividade" (CORSINO; VILELA; TRAVASSOS, 2014, p. 109). Um aprender tecido no encontro dialógico e alteritário que tem a ficção como elo.

Antônia, Bento, Bruno, Carolina, Giovana, Maitê, Marcela, Pedro, Vanessa e Vitória. Dez crianças, dez diferentes modos de ver e entender o mundo. A pesquisa proporcionou que nós formássemos uma comunidade de leitores. As oficinas literárias constituíram-se como um espaço tempo para ler e discutir sobre a vida, a partir da literatura infantil digital. Uma proposta de fruição e de crítica, pois a experiência de ler e de dialogar sobre o lido são indissociáveis.

Peter Hunt (2010), nessa linha, indica que lançar perguntas sobre a obra, explorando as impressões e os sentimentos das crianças, é uma estratégia formativa importante. Considerando essa perspectiva, construímos uma metodologia de pesquisa que envolveu experimentar junto com as crianças o efeito de ler literatura 
na tela. Essa dinâmica, de compartilhar leituras, de se afetar com as crianças, provocou em todos uma postura crítica. Ao mesmo tempo que eu trazia questões que versavam sobre a forma e o conteúdo das ficções, os leitores também compartilhavam dúvidas e perguntas que incitavam conversas muito interessantes. Uma colaboração e um compartilhamento de saberes horizontal que abarcou desde aspectos mais técnicos da leitura - como a descoberta de um recurso interativo, por exemplo - até a construção de conceitos e a partilha de experiências pessoais - aspectos que serão explorados nas análises a seguir.

Ao longo das oficinas, lemos e conversamos sobre nove aplicativos literários. A leitura na tela provocou o encontro das crianças com uma literatura que tem a multimodalidade e a não linearidade como marcas constitutivas. Gestos e experiências de leitura que surgiram a partir do entrelaçamento entre texto, imagem, movimento e som. O tablet, considerado um dispositivo móvel individual, tornou-se suporte para uma leitura compartilhada. Um desvio metodológico que funcionou. Ao alternar momentos de interação entre as duplas/trios e entre todo o grupo, configuramos uma dinâmica que favoreceu a leitura e a discussão coletiva. Encontros que permitiram apreciar obras, experimentar jogos, criar histórias, fazer gravações de voz, cantar, dançar, tirar fotos, narrar e conversar.

A leitura foi mobilizadora de conversas sobre a vida, sobre o que nos atravessa. Uma prova de que a leitura na tela não é sempre dispersiva. Ler literatura infantil digital na escola é um modo de suspender o tempo da produtividade e de se deixar assombrar pelo ficcional, de transitar entre os limiares da obra. Nessa perspectiva, ressaltamos a potência do ato de ler junto, de compartilhar leituras, em especial com as crianças, independentemente do suporte. Os encontros possibilitaram que os sentidos construídos fossem socializados e se tornassem coletivos, compostos, potencializando a criação e a imaginação de todos os envolvidos. Os instantes abaixo dialogam com essas questões. Vejamos.

\section{O que é um monstro?}

Pesquisadora: Eu posso fazer uma pergunta? O que é um monstro?

Vitória: É um negócio muito assustador que eu não gosto.

Pedro: Vive no terror!

Giovana: É um monstro bem esquisito que assombra os humanos, principalmente as crianças. Bento: No escuro, na noite. Por isso que eu fico na cama dos meus pais. 
Pedro: E também, sabe, os monstros vivem no filme de terror.

Bento: Às vezes, eles fogem quando veem uma espada.

Pesquisadora: Eles sentem medo de espada?

Bento: É, porque corta eles.

Vitória: Mas tem monstro que come mosquito para proteger a gente.

Bento: Quem?

Vitória: Morcego marrom.

Pesquisadora: Morcego é monstro?

Antônia: O morcego marrom não, porque ele não suga a gente.

Pedro: Morcego é vampiro!!!!!

Bento: É. Quando ele faz assim com a capa - diz fazendo o gesto de cobrir o rosto. E ele tem os dentes afiados.

Pedro: Vampiro não gosta de alho e ele morre com a luz.

Bento: Eu vi nos Minions que quando aparece a vela e o sal, o vampiro morre e vira terra.

Antônia: Não. Vira poeira.

Bento: Terra-poeira.

Antônia: Não. É outra coisa. Sabe aqueles queimadinhos?

Pesquisadora: Cinzas?

Antônia: Não é um queimadinho que aparece no desenho animado, tipo uma chama. Aí, vira vários farelinhos.

Pesquisadora: Farelinhos de fumaça?

Antônia: Isso! Na verdade são farelinhos do fogo.

Pedro: Eu posso falar uma coisa? Vampiro gosta de sangue.

Bento: Quando o vampiro suga o sangue do humano, o humano morre. Ele morre.

Vitória: Mas o humano não vira vampiro?

Bento: Às vezes ele morre e às vezes vira vampiro. No desenho do Scooby-Doo ele vira vampiro.

$(\ldots)$

Pesquisadora: E aí? Qual monstro vocês acharam mais assustador? 
Vitória: Nenhum!!!

Pesquisadora: Nenhum? Ué, mas vocês falaram no começo do nosso encontro que monstros são sempre assustadores!

Vitória: Mas aqui estava tudo desenhado, então não deu medo. Se fosse foto de verdade ia assustar.

Pedro: Eu achei eles engraçados.

Pedro: Eu e Antônia gostamos muito do Drácula.

Bento: Eu também gostei.

Antônia: Ele não foi assustador, foi bem tranquilo (Oficina 5 - 22/08/2018).

Criado por Daniel Kondo e Augusto Massi, o aplicativo Monstros do Cinema faz referência ao livro homônimo também publicado pela Sesi-SP Editora. Foi um dos finalistas na categoria Infantil Digital do Prêmio Jabuti, em 2017. Disponibilizado apenas para o sistema operacional iOS, o aplicativo pode ser baixado gratuitamente. Na produção, os monstros do cinema foram fatiados em três pedaços: cabeça, tronco e membros. Após embaralhar as partes, o leitor é convidado a montar o seu próprio monstrengo. Os autores buscaram conceber uma obra que reunisse ao mesmo tempo o livro brinquedo e o livro conteúdo. O primeiro pela proposta lúdica de criar o seu próprio monstro e o segundo pela pesquisa fílmica que originou uma interessante linha do tempo, a partir da descoberta da origem de cada um dos monstros.

O instante "O que é um monstro?" envolveu dois momentos de discussão: uma roda antes da leitura do aplicativo e outra no fim da oficina literária. A questão, levantada por mim, mobilizou o grupo em vários sentidos. Pedro, Vitória, Giovana, Antônia, Maitê e Bento tinham um mesmo pensamento: a de que monstros são sempre assustadores. Entretanto, é possível ver as crianças, em suas hipóteses, transitarem entre o real e o ficcional ao longo de toda a discussão. Para o grupo, há "monstros que vivem no filme de terror", como anunciou Pedro e os que vivem "no escuro, na noite" e que fazem o menino Bento querer ir para cama dos pais.

Em diálogo com esta questão, Vigotski (2009) assinala que a criação é uma ação fundamental do homem e que toda e qualquer criação se origina da complexa relação entre imaginação e realidade. Nesse viés, o autor destaca quatro pontos: i) a imaginação se constrói sempre a partir da realidade; ii) a experiência pode vir da fantasia, pois ela permite ao sujeito imaginar o que ainda não viu, o que não vivenciou em sua experiência pessoal; iii) a imaginação vincula-se reciprocamente à 
emoção, assim, os sentimentos influem na imaginação, e esta, nos sentimentos; iv) a imaginação pode representar algo inteiramente novo, e esta imagem, convertida em objeto, influir na realidade.

A possibilidade de encontro com o outro por meio da linguagem literária permite a construção de imagens e cenas mentais, ampliando a relação do homem com o mundo. Nesse circuito, há ainda a emoção, que se manifesta nesse trânsito entre realidade e ficção. A lei da dupla expressão dos sentimentos, proposta pelo autor, parte do pressuposto de que o nosso estado emocional influencia de forma direta a nossa experiência. Assim, as emoções são expressas na linguagem, na nossa organização de ideias, e também no corpo, através de reações de ordem física. Esse tom afetivo, emocional, ao alterar a imaginação, altera também a nossa relação com a realidade. É isso que faz com as emoções experimentadas no encontro com a ficção tornem-se reais. A ficção influencia os "nossos sentimentos e, a despeito de essa construção por si não corresponder à realidade, todo sentimento que provoca é verdadeiro, realmente vivenciado pela pessoa, e dela se apossa" (VIGOTSKI, 2009, p. 28). Assim, o medo do monstro, provocado pelas ilustrações ou pela leitura de um texto, torna-se completamente real, como foi apontado no instante por Bento.

As conexões das crianças mostraram-se também interdiscursivas. Vemos de forma explícita a relação com outras linguagens e referências. Seus pressupostos sobre monstros trazem discursos do filme dos Minions e do desenho do Scooby-Doo. Pedro, Bento e Antônia anunciam seus saberes sobre vampiros e misturam realidade e fantasia em suas enunciações, associando a imagem do morcego como animal predador que "come mosquito para proteger a gente" e também como vampiro. Dizem com gestos e palavras o que sabem sobre esse monstro: experimentam seu movimento de sumir e aparecer com a capa, relacionam os "dentes afiados" à ação de sugar o sangue humano, anunciam que ele "não gosta de alho e ele morre com a luz" e que, quando morre, "vira terra" / "vira poeira" / "vira terra-poeira". Uma negociação de sentidos construída de forma dialógica, pautada na reação de uma palavra a outra palavra (BAKTHIN, 2011). Uma brincadeira com a linguagem, que faz com que Antônia busque explicar o seu pensamento na imagem vista na tela, num desenho animado, chegando a conclusão de que os vampiros, quando exterminados, transformam-se em "farelinhos do fogo".

A leitura do aplicativo e a socialização discursiva, entretanto, desconstruíram a ideia inicial de que todos os monstros são assustadores. A ilustração, o traço cômico apresentado na tela, divertiu as crianças. Como apontou Vitória, "estava tudo desenhado, então não deu medo". Observamos assim que a imagem é capaz 
de apresentar várias camadas de leitura. Enquanto signo, as imagens possuem códigos e sintaxes próprias, expandindo os processos ficcionais. Em consonância com essas considerações, Corsino (2011, p. 155) aponta que as ilustrações são como prismas: "Ao mesmo tempo em que são figurativas e fazem ver personagens e elementos-chaves presentes no texto verbal, também trazem algo abstrato, difuso, sem fronteiras muito delimitadas, evocando o que não foi enunciado”. A produção de "Monstros de Cinema" provocou nas crianças um olhar sensível que abarcou forma e conteúdo, inspirando discussões sobre a arte e a vida.

O próximo instante apresenta a discussão coletiva sobre os sentimentos experimentados na tela pela personagem Quadradinha de Papel, do aplicativo "Mãos mágicas" e pelas crianças na vida real.

Criado por Teresa Yamashita, o aplicativo Mãos Mágicas faz referência ao livro homônimo também publicado pela Sesi-SP Editora, em 2013. Disponível para o sistema operacional $i O S$, o aplicativo literário foi um dos vencedores da categoria Infantil Digital do Prêmio Jabuti, em 2016, ficando em segundo lugar. A obra narra a história dos irmãos Quadradinha e Fininho de Papel. Após ver o vento carregar Fininho para muito longe, Quadradinha dobra-se toda, entristecida. Mas, o encontro com um sapo a faz descobrir o origami. Dobrando e desdobrando, ela se transforma em outros animais. Vira borboleta, urso panda, gato, girafa, macaco, pássaro. Quadradinha viaja ao redor do mundo para encontrar seu irmão. Após chegar a uma casa amarela, encontra Fininho. Na casa da menina Sadako, os dois descobrem que ela também conhece a arte do origami. Juntos, enfim, eles voam em busca de novas aventuras.

\section{Sobre susto, tristeza e irritação}

Maitê: Sabe, eu gostei quando a Quadradinha e o Fininho se encontraram.

Pedro: Eu não gostei muito.

Maitê: Não? Nem quando a Quadradinha cresceu e ficou assustada lá na casa amarela.

Como Pedro não responde, lanço um dos trechos comentados por Maitê como questão para o grupo.

Pesquisadora: Pessoal! A Maitê gostou da parte que a Quadradinha de papel ficou assustada. Alguém aqui já ficou assim?

Antônia: Eu fico quando eu acordo de madrugada, porque eu sempre ouço um barulhinho. Aí eu vou direto para o quarto da minha mãe e eu deito lá e durmo. 
Giovana: Eu também às vezes fico assim de noite. Porque está escuro, sabe?

Bento: Eu não. Mas, às vezes, eu fico triste.

Maitê: Igual a Quadradinha!

Pesquisadora: Verdade! A Quadradinha ficou triste também, toda dobradinha.

Maitê: Eu já fiquei triste quando o meu pai me deixou de castigo.

Pesquisadora: Eu já fiquei também. Tem vezes que a gente fica triste, mesmo.

Pedro: Quem brigou com você?

Pesquisadora: Às vezes não acontece briga, mas mesmo assim você fica triste.

Vitória: Eu já fiquei um tiquinho de nada, quando minha amiga não quis ficar comigo.

Pedro: Eu fiquei quando a minha mãe e o meu pai se separaram.

Antônia: Eu fico muito, mas muito irritada quando eu falto a escola.

Pesquisadora: E tem diferença entre ficar irritada e ficar triste?

Antônia: Irritada é quando a pessoa fica muito brava. É um outro jeito de dizer que está brava.

Giovana: Mas é diferente de ficar triste.

Vitória: A gente pode se sentir triste e irritado, ué!

Antônia: É! Mas não é igual. É outra sensação (Oficina 12 - 02/10/2018).

No instante "Sobre susto, tristeza e irritação", apesar de Maitê iniciar o diálogo explicitando para o grupo seu trecho favorito da ficção digital, a reverberação aconteceu a partir da minha intervenção. Diante do silêncio do grupo frente à questão trazida pela menina, busquei em sua enunciação uma questão para pensarmos juntos: "A Maitê gostou da parte que a Quadradinha de papel ficou assustada. Alguém aqui já ficou assim?”. A proposta mobilizou as crianças a dialogarem sobre a obra a partir de suas experiências pessoais.

Antônia falou sobre o susto de ouvir barulhinhos quando acorda de madrugada. Giovana também partilha do sentimento, mas relaciona-o ao escuro. Bento traz à tona outro sentimento: a tristeza. As crianças continuam a conversa, compartilhando momentos da vida em que se sentiram assim, "igual a Quadradinha" retratada no aplicativo.

Castigo, briga, solidão, separação. Temas que perpassam a vida e que atingem crianças e adultos sem distinção. A compreensão de que as crianças são afetadas 
pelo campo social tanto quanto nós adultos e que, por isso, necessitam de espaços e tempos para dizer sobre seus medos e angústias, infelizmente, não é um consenso. $\mathrm{O}$ entendimento de que o tom amargo presente na literatura pode ser uma potente via de experimentação dos sentimentos contraditórios que perpassam a relação com o outro e com o mundo precisa ganhar força na sociedade contemporânea. Por fim, há ainda uma discussão sobre irritação. Um diálogo que fez surgir entre as crianças uma percepção coletiva de que, às vezes, os sentimentos se misturam dentro da gente.

Os instantes "O que é um monstro?" e "Sobre susto, tristeza e irritação" apresentaram o compartilhamento de saberes entre uma comunidade de leitores. As crianças, a partir da leitura dos aplicativos, construíram e negociaram sentidos e socializaram experiências pessoais, demonstrando que as conversas sobre o que lemos são fundamentais na formação leitora.

\section{Considerações finais}

Em grande parte das vezes, observamos que a experiência da leitura termina junto com a história. A pesquisa apontou que as conversas sobre a obra são tão importantes quanto o ato de ler. Nesse sentido, é importante reservar tempos e espaços para o diálogo, pois lançar perguntas sobre a obra, explorar as impressões e os sentimentos das crianças, amplia o processo formativo do leitor (HUNT, 2010).

Entretanto, é importante salientar que uma boa pergunta não apresenta respostas fechadas, prontas, como os usuais sim/não, gostei/não gostei. Considerando essa perspectiva, é importante pensar em questões que reflitam sobre a forma e o conteúdo das ficções, questões que nos afetem enquanto adultos, que nos provoquem a ouvir as crianças e também a dizer nossas impressões, incitando um espaço interlocutivo interessante para todos.

Os instantes capturados apontam que a literatura infantil digital provoca um trânsito entre o real e o ficcional. Um ir e vir sem fronteiras definidas que permitiu conversarmos sobre obra e vida. Consideramos que essa dimensão expressiva e socializadora a partir da leitura na tela foi possível pela metodologia dialógica proposta na pesquisa. A perspectiva de ler e de discutir as obras, de encontrar espaço e tempo para conversar, de escutar o que as crianças trazem e de nos deixar afetar por isso, lançando novas questões, potencializou a leitura e a socialização na escola.

Considerado por muitos como uma experiência individual, o encontro com o digital na escola através da leitura de aplicativos, reafirmou que a literatura, mesmo 
na tela, é capaz de criar um espaço tempo para o encontro, o diálogo, a brincadeira. As oficinas constituíram-se como experiências significativas, ampliando os processos de imaginação e de criação das crianças.

\section{Referências}

BAKHTIN, Mikhail. Estética da criação verbal. Trad. Paulo Bezerra. 6. ed. São Paulo: Martins Fontes, 2011.

BARRENTO, João. Walter Benjamin: limiar, fronteira e método. Olho d'água, São José do Rio Preto, v. 4, n. 2, p. 41-51, jul./dez. 2012.

BENJAMIN, Walter. Passagens. Belo Horizonte; São Paulo: Editora UFMG; Editora Imprensa Oficial do Estado de São Paulo, 2006.

BENJAMIN, Walter. Magia e técnica, arte e política. São Paulo: Brasiliense, 2012. (Obras escolhidas, v. I).

CHARTIER, Roger. As aventuras do livro: do leitor ao navegador. São Paulo: Unesp, 1998.

CORSINO, Patricia. A tela e a escrita, a escrita e a tela: interações e leitura. In: MARTINS, Aracy et al. (org.). Livros \& telas. Belo Horizonte: Editora UFMG, 2011. p. 149-159.

CORSINO, Patricia; VILELA, Rafaela; TRAVASSOS, Sonia. O livro e o corpo: gestos e movimentos de leitura na escola e na biblioteca. Revista Contemporânea de Educação, Rio de Janeiro, v. 9, n. 18, p. 259-280, jul./dez. 2014. Disponível em: https://revistas.ufrj.br/index.php/rce/ article/view/1859/1693. Acesso em: jun. 2019.

LEVY, Pierre. Cibercultura. São Paulo: Editora 34, 1999.

HAYLES, N. K. Literatura eletrônica: novos horizontes para o literário. São Paulo: Global; Fundação Universidade de Passo Fundo, 2008.

HUNT, Peter. Crítica, teoria e literatura infantil. São Paulo: Cosac Naify, 2010.

MACEDO, Nélia; SANTOS, Nubia; FLORES, Renata; PEREIRA, Rita. Encontrar, compartilhar e transformar: reflexões sobre a pesquisa intervenção com crianças. In: PEREIRA, R. M. R.; MACEDO, N. M. R. (org.). Infância em Pesquisa. Rio de Janeiro: Nau, 2012. p. 87-107.

MARTÍN-BARBERO, J. Tecnicidades, identidades, alteridades: mudanças e opacidades da comunicação no novo século. In: MORAES, D. Sociedade midiatizada. Rio de Janeiro: Mauad X, 2006. p. 51-79.

MENEGAZZI, D.; SYLLA, C.; PADOVANI, S. Hotspots em livros infantis digitais: um estudo de classificação das funções. Portugal: DIGICOM International Conference on Digital Design \& Communication, 2018.

NIKOLAJEVA, Maria; SCOTT, Carole. Livro ilustrado: palavras e imagens. São Paulo: Cosac Naify, 2011. 
PEREIRA, Rita Marisa Ribes. Um pequeno mundo próprio inserido num mundo maior. In: PEREIRA, R. M. R.; MACEDO, N. M. R. (org.). Infância em Pesquisa. Rio de Janeiro: Nau, 2012. p. 25-57.

RAMADA PRIETO, Lucas. Esto no va de libros: literatura infantil y juvenil digital y educación literaria. 546f. Tese (Doutorado em didática da língua e da literatura) - Faculdade de Ciências da Educação, Universidade Autônoma de Barcelona, Barcelona, 2017.

RAMADA PRIETO, Lucas. Infantil, digital, aumentada y virtual: los mil y un apellidos de una realidade literaria. Diablotexto Digital, Espanha, v. 3, p. 8-31, 2018.

VIGOTSKI, Lev. Imaginação e criação na infância: ensaio psicológico: livro para professores. Apresentação e comentários Ana Luiza Smolka; tradução Zóia Prestes. São Paulo: Ática, 2009.

VILELA, Rafaela. Literatura infantil digital: arte, infância e tecnologia na escola. $191 \mathrm{f}$. Tese (Doutorado em Educação) - Faculdade de Educação, Universidade Federal do Rio de Janeiro, Rio de Janeiro, 2019. 